\title{
HOW CONIFER DIVERSITY AND AVAILABILITY INFLUENCE THE ABUNDANCE AND BIOLOGY OF THE RED CROSSBILL
}

\author{
THOMAS P. HAHN $\uparrow$ ELIZABETH M. SCHULTZ \\ UNIVERSITY OF CALIFORNIA † DAVIS, CA
}

\section{$\downarrow \quad$ ABSTRACT}

In order to understand the distributions and abundances of animals, many environmental factors must be considered, particularly the availability of food resources. Food resources are especially important to nomadic species that move in response to the spatial and temporal availability of these specific food resources that are critical to their survival. An example of such nomadic species is the red crossbill (Loxia curvirostra), which specializes on conifer seeds, a resource that significantly varies both temporally and geographically. Thus, crossbills will move large distances each year to find areas with abundant conifer seeds. While conifer seeds impact the distribution, abundance, and reproductive rate of crossbills, it is likely not the only factor driving these patterns. To truly understand what drives the distribution and abundance of crossbills across North America, further study is needed not only on how external environmental factors such as food abundance affect these patterns, but how tradeoffs among internal physiological processes such as reproduction and survival related processes such as immune function may affect when crossbills irruptively migrate or whether or not reproduction occurs. Historically, research to understand how organisms orchestrate their annual cycles with respect to these costly and conflicting physiological processes has focused narrowly on seasonal breeders that constrain reproduction to times of year when thermoregulatory demand is low (i.e., summer), which provide limited opportunities to reveal how physiological costs of different processes may interact with environmental conditions to influence the evolution of investment strategies. In this study, we are examining how the diversity, abundance, and size of cone crop of conifers influence both 1) the quantity and diversity of red crossbills, as well as 2) their seasonal modulation in investment patterns in reproduction and self-maintenance processes such as immune function in Grand Teton National Park, where crossbills can be found breeding in both summer and winter. Preliminary results from this study have indicated that both conifer diversity and cone crop size affect overall quantity and vocal type diversity of crossbills in Grand Teton National Park, as well as affecting their investment in reproduction and immunity. Overall, results from this study will provide information on how species in general and crossbills, specifically, respond to rapidly changing environments, which has become increasingly important in light of the effects of anthropogenic change.

\section{$\uparrow \quad$ INTRODUCTION}

There are many interacting factors that may affect distributions and abundances of animals, including tolerances of physical environmental factors (Brown and Fedmeth 1971), competition (Connell 1983), predation (Hahn and Denny 1989), disease (Hochachka and Dhondt 2000), and the availability of crucial food resources (Brown et al. 1995). In particular, it has been well documented that food resource availability has pronounced effects on the distribution and abundance of those nomadic species that move in direct response to the spatial and temporal availability of these food resources (Anderson 1980, Kelsey et al. 2008). One such nomadic species is the red crossbill (Loxia curvirostra), which specializes on 
extracting seeds from conifer cones (Groth 1993). Further, crossbills can be categorized into ten vocal types that are known to specialize on one or two "key" conifers (Groth 1993). Because most conifers are mast seeders and annually produce erratic quantities of cones and seeds (Koenig and Knops 2000), crossbills will move large distances each year to find areas with abundant conifer seeds (Adkisson 1996). While conifer seed impact on the distribution, abundance, and reproductive rate of crossbills (e.g., during a large cone year, crossbills can have as many as four successful clutches between summer and spring of the following year (Adkisson 1996)), it is not the only factor driving these patterns. For example, even in low cone years, crossbills will still reproduce (Kelsey et al. 2008), but potentially at a cost to survival or selfmaintenance processes (Schultz unpublished data). Thus, to truly understand what drives the distribution and abundance of different crossbill types across North America, further study is needed not only on how external environmental factors such as food abundance affect these patterns, but how tradeoffs among internal physiological processes such as reproduction and survival related processes such as immune function may affect when crossbills may irruptively migrate or whether or not reproduction occurs.

Even though much study has been devoted to understanding how organisms allocate limited resources between reproduction and survival-related processes like immune function (e.g., Martin et al. 2008, Zera and Harshman 2001), the majority of this research has focused narrowly on studies of seasonal breeders, those organisms that temporally segregate different components of the annual cycle and restrict the most demanding processes to times when resource availability is high and environmental conditions are benign (Menaker 1971, Gwinner 1986, Nelson and Demas 1996). This focus is problematic because many organisms do not follow these annual schedules and so allocation patterns garnered from just seasonal organisms may not apply to all organisms. Thus, by studying these tradeoffs in an opportunistic breeder such as the crossbill, we will gain new knowledge of how harsh environmental conditions and reproductive effort may interact to shape investment in survival, specifically immune function.

\section{Study species}

Red crossbills can be found reliably in Grand Teton National Park every year, although the overall abundance and diversity of vocal types present is highly variable from year to year and is known to be somewhat dependent on the size of the cone crop
(Kelsey et al. 2008, Hahn 1998). In this report, we will provide recent data on how the diversity, abundance, and size of cone crop of conifers influence both 1) the quantity and diversity of red crossbills, as well as 2) their seasonal modulation in investment patterns in reproduction and self-maintenance processes such as immune function.

\section{$\downarrow \quad$ METHODS}

Objective 1: how the diversity, abundance, and size of cone crop of conifers influence the quantity and diversity of red crossbills.

\section{Study site and species}

In Grand Teton, the dominant conifers are lodgepole pine (Pinus contorta), Douglas-fir (Psuedotsunga menziesii), Engelmann spruce (Picea engelmanii), blue spruce (Picea pungens), and subalpine fir (Abies lasiocarpa). This area is ideal for studying the diversity and abundance of red crossbill types because Type 5 are present every year due to their specialization on lodgepole pine, which produce cones every year (Burns and Honkala 1990), with periodic invasions of other types $(2,3$, and 4$)$ in response to large cone crops on Douglas-fir and spruce (Kelsey et al. 2008). Thus, we have focused on red crossbill types 2, 3, 4, and 5, which specialize, but not exclusively, on ponderosa pine, western hemlock, Douglas-fir, and lodgepole pine, respectively (See Figure 1). We use survey sites that were selected in 2006 as stratified random samples of different coniferous habitats in the Grand Teton region (Kelsey et al. 2008). Specifically, ten areas that varied in the relative dominance of conifers that are important food sources for types 2-5 of red crossbills were selected: lodgepole pine, Douglas-fir, and Engelmann and blue spruce. These areas in the park and National Forest are 1) Leidy, 2) Signal Mountain, 3) String Lake, 4), Shadow Mountain, 5) Death Canyon, 6) Granite Canyon, 7) Mosquito Creek, 8) Saw Mill Ponds, 9) Sheep Creek, and 10) Philips Pass. Within these ten areas, there are 3-5 survey or point-count sites, which were randomly selected to be a random distance between 100-500 meters from the start of a road or trail.

We used 15-minute point counts at each site to quantify the relative abundances of the four different crossbill types, following standard methods used by Kelsey et al. (2008) and outlined in Ralph et al. (1993). During the point counts, we note all detections of each type, including the number of birds detected if seen, distinguishing among types by ear. 


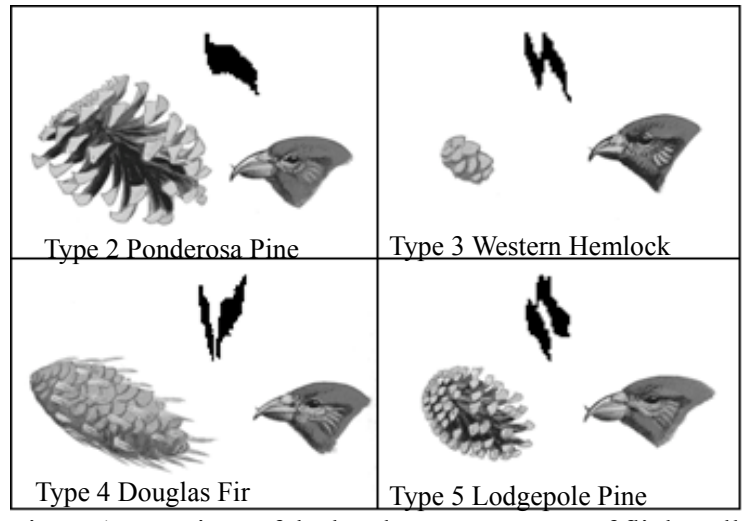

Figure 1. Drawings of the heads, spectrograms of flight calls, and key conifer cones of the four crossbill vocal types studied by Benkman (1993). Crossbills call frequently both while in flight and while perched, reliably call from cages after being captured, and when released after banding. All of these call types are readily identifiable by ear.

\section{Conifer composition and cone crop}

To evaluate local habitat selection and diet selectivity of different red crossbill types, we quantified 1) conifer composition by estimating the percent cover and availability of key conifers at each point-count site (site-level percent cover using Quadrat samples of mature trees and calculate percent cover as total number of each species divided by total number of trees across the quadrat), and 2) the availability of key conifers from a cone crop score which ranges from $0-5$ ( 0 having no cones and 5 having large number of cones on cone-bearing section of tree) on 10-20 trees of each species present within 50 meters of the point-count site. Relative abundance of each crossbill type was estimated by reviewing field notes.

Objective 2: how the diversity, abundance, and size of cone crop of conifers influence the seasonal modulation in investment patterns in reproduction and self-maintenance processes such as immune function in red crossbills.

\section{Capture methods}

We attract crossbills using live caged decoys. Decoys call loudly when they hear birds of their own type, and birds are caught in mist nets when they approach the decoys (Adkisson 1996). If necessary, we supplement vocalizations from the decoy with playbacks of crossbill vocalizations. From each bird captured, we collect approximately $200 u \mathrm{~L}$ of blood into a pre-sterilized, heparinized capillary tube. We centrifuge the blood and freeze plasma at $-20^{\circ} \mathrm{C}$ until hormone and immune assays (described below).

\section{Measuring reproductive potential}

Reproduction is very energetically costly in birds but is essential to fitness (Nelson and Demas 1996). Significant energetic investment is required for attracting and keeping a mate, producing, laying and incubating eggs, and provisioning nestlings (Monaghan and Nager 1997). In addition, investing energy into increased fecundity or parental care in one breeding cycle might subsequently affect survival and future reproduction (Dhondt 2001).

Cloacal protuberance (CP) length in freeliving male red crossbills significantly predicts testis length and therefore offers a non-invasive estimation of reproductive status (Cornelius 2009, Wingfield and Farner 1976). Males with cloacal protuberance lengths of $5 \mathrm{~mm}$ or larger are categorized as having high reproductive potential; males with cloacal protuberances of 3 to $5 \mathrm{~mm}$ are medium, and $3 \mathrm{~mm}$ or less are considered low (Cornelius 2009, Wingfield and Farner 1976). In female red crossbills, brood patch (BP) stage significantly predicts ovary condition (Cornelius 2009, Wingfield and Farner 1976). Females with brood patches $>0$ are considered high, whereas females with brood patches $=0$ or below are considered low reproductive potential. Briefly, a dry and fully feathered breast scored a 0 ; a dry but bare (i.e., without feathers) breast scored a 1; a bare breast with increased vascularization and/or mild edema scored a 2; a bare, vascularized breast with full edema scored a 3; and a bare and wrinkly breast scored a 4 (i.e., post-full edema) (Nolan and Ketterson 1983). Because estimations of cloacal protuberances and brood patches are not a perfect prediction of reproductive condition, we have supplemented this data with 1) lavage of the cloacal protuberance to collect semen and measure presence of sperm, and 2) utilizing hormone profiles (androgens and estradiol) extracted via a competitive binding radio-immuno assay (RIA) from blood samples.

\section{Measuring immune function (survival-enhancing process)}

Immune function contributes to survival by detecting pathogens and limiting infection, but because maintenance of immunity can be costly (e.g., Schmid-Hempel and Ebert 2003), many environmental and physiological variables have been hypothesized to cause investment in immunity to vary (Buehler et al. 2008, Martin et al. 2008, Nelson et al. 2002). Broadly, the immune system can be divided into two main components: innate and adaptive. Innate 
immune function provides an immediate and nonspecific response to a pathogen and can be further categorized into constitutive and induced responses. Adaptive or acquired immunity is activated by the innate response to produce specific antibodies against the pathogen (Martin et al. 2008, Lee 2006).

We specifically measured constitutive immunity because it provides a first line of defense against many pathogens and must always be maintained on some level, which create costs that may be important in mediating physiological trade-offs (Martin et al. 2008). To measure constitutive immunity in crossbills, we utilized 1) complement and natural antibody activity via a hemolysishemagglutination assay (Matson et al. 2005), 2) bacterial-cidal assay that measures the capacity of whole blood to limit a bacterial/microbial infection (Millet et al. 2007), and 3) differential white blood cell counts, a simple, gross measure of innate immunity obtained from a simple blood smear (Campbell 2007).

\section{$\downarrow \quad$ PRELIMINARY RESULTS}

Objective 1: How the diversity, abundance, and size of cone crop of conifers influence the quantity and diversity of red crossbills.

As demonstrated by Kelsey et al. (2008), the crossbill types may be specialized for general resource classes (groups of conifer species) rather than single resources. In Grand Teton, type 2s most frequently occur in areas dominated by spruce (both blue and Engelmann) and Douglas-fir, type 3s with Engelmann spruce, type $4 \mathrm{~s}$ with Douglas-fir, and type 5 with lodgepole pine (Kelsey et al. 2008). Additionally, type $2 \mathrm{~s}$ will selectively forage on Douglas-firs, type $3 \mathrm{~s}$ will selectively forage on Engelmann spruce in summer and Douglas-fir in winter, while types 4 and 5 will selectively forage on Douglas-fir to avoid lodgepole pine (Kelsey et al. 2008).

Recent data collected from 2010-2013 (Figures 2 and 3) further demonstrate that both conifer diversity and cone crop abundance significantly contribute to crossbill type quantity and diversity in Grand Teton National Park (see Figure 4). To clarify, cones begin to develop on the trees in early summer (June-July) and are typically harvested by crossbills and other animals up until late spring of the following year (Koenig and Knops 2000). Thus, a heavy cone year like 2011 would last from June/July 2011 through late spring of 2012. Our data suggest that type 5 crossbills are present in years with both low and heavy

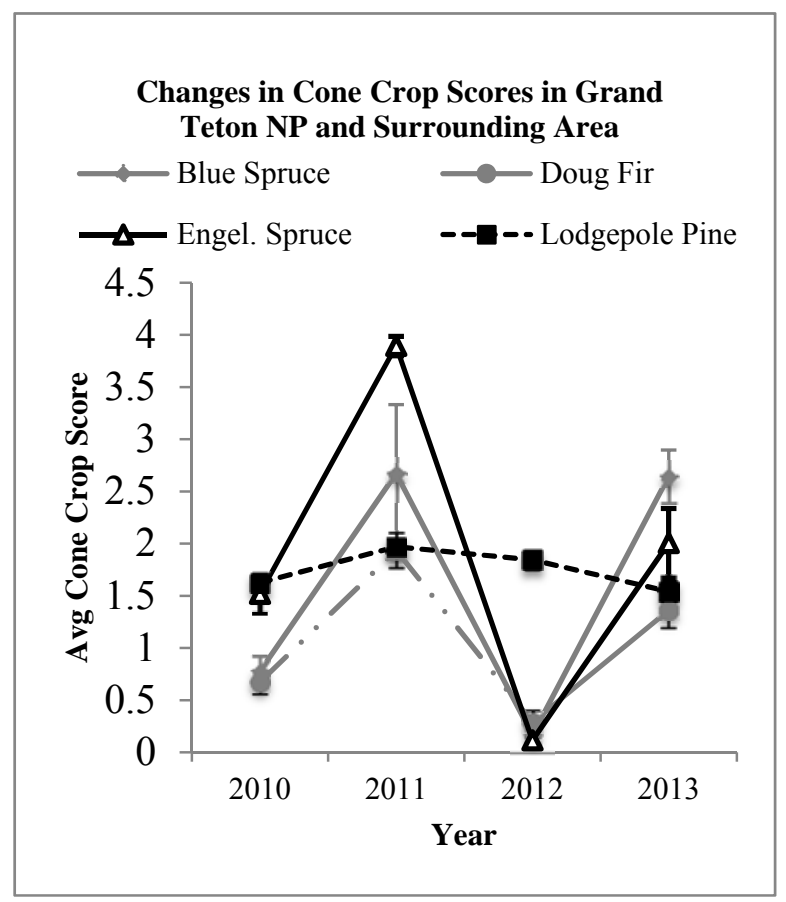

Figure 2. Average cone crop abundance in Grand Teton National Park in 2010, 2011, 2012, and 2013. Lodgepole pine cone abundance appears to be fairly consistent, averaging around 1.5 (out of a max score of 5) every year, whereas the other conifer species fluctuate more dramatically from year to year. 2011 saw the highest cone abundance across all key conifer species, with Engelmann spruce having the largest crop (average score of 3.9). Bars represent standard error of the mean (SEM).

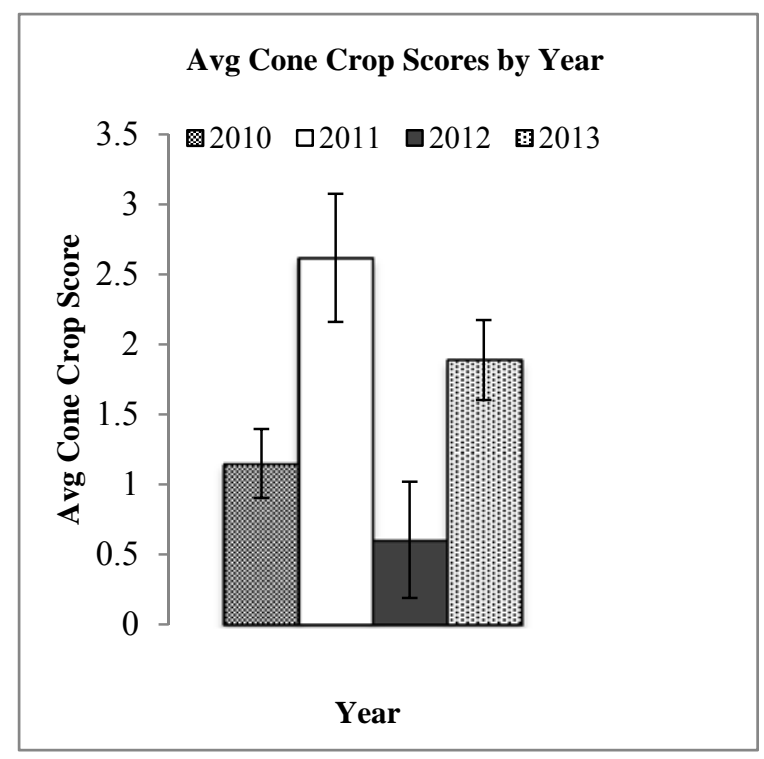

Figure 3. Average cone crop abundance (combining averages of blue spruce, lodgepole pine, Engelmann spruce, and Douglas-fir). 2011 saw the overall highest cone abundance, with 2010, 2012, and 2013 showing significantly lower overall cone abundances. Bars represent standard error of the mean (SEM). 
conifer cone crops, whereas other vocal types (2,3, and 4) are only present in heavy cone years such as 2011 (Figure 4). However, juveniles (hatch year) of vocal types $(2,3$, and 4$)$ were numerous in summer of 2012 (a low cone year), and were likely born in winter or spring of 2012.

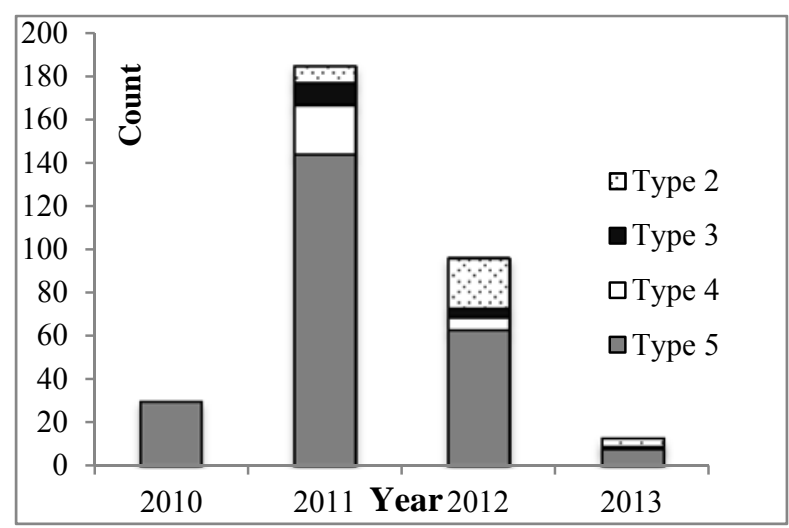

Figure 4. Red crossbill type abundance by year. In 2010 (low cone year), the only crossbill types caught via mist net were type 5. In 2011, types, 2, 3, 4, and 5 were all caught, with type 5 being the most abundant. We caught primarily type $5 \mathrm{~s}$ in 2012 , but did catch young (hatch year) type $2 \mathrm{~s}, 3 \mathrm{~s}$, and 4 s. Only 14 birds were caught in 2013 , mostly type 5 s and $2 \mathrm{~s}$.

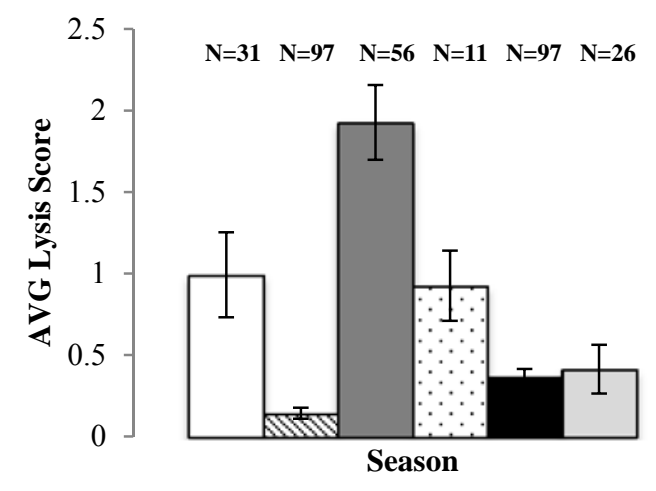

Figure 5. Seasonal pattern of lysis scores (complement level) in red crossbills. Highest lysis scores are seen in the summer, with declining scores during fall, winter, and spring. Lysis scores are also higher in years with heavier cone crops (2011). Bars represent S.E.M.

Objective 2. How the diversity, abundance, and size of cone crop of conifers influence the seasonal modulation in investment patterns in reproduction and self-maintenance processes such as immune function in red crossbills.
Data from 2010-2013 have demonstrated that years in which the cone crops of key conifers are more abundant, crossbills have higher reproductive potential and immune function (as measured by two different immune assays), which is most likely the result of having more food resources available to invest in multiple competing, energetic processes.

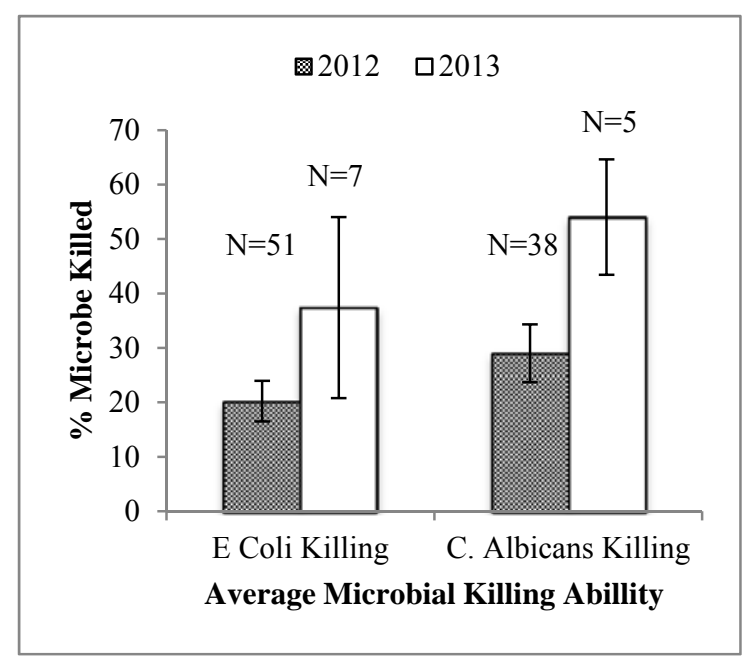

Figure 6. Average microbial killing ability of red crossbills summer of 2012 and 2013. The killing of both microorganisms is mediated by different mechanisms: E.coli killing is mediated by complement proteins, whereas C.albicans killing is mediated by white blood cell phagocytosis.

How size of cone crops affects overall crossbill immunity: 1) Results from hemolysishemagglutination assay: The hemolysishemagglutination assay uses a serial dilution of plasma and rabbit red blood cells to measure the activation of humoral component of constitutive innate immunity, specifically measuring complement levels via lysis ability and natural antibodies via agglutination level; higher lysis and agglutination scores typically equate to higher levels of immune function (Matson et al. 2005). When comparing seasonal and annual variation of both lysis scores (complement level) and agglutination scores (natural antibody level), average lysis scores exhibit distinct annual and seasonal patterns (Figure 5). Agglutination scores did not exhibit annual or seasonal variation (figure not shown). 2) For this assay, we measured the ability of crossbill whole-blood (not just plasma) to eliminate (or "kill") two species of microbe: Escherichia coli and Candida albicans. E. coli killing is primarily mediated by complement proteins, whereas $C$. albicans killing is primarily mediated by white blood cell phagocytosis, thus probing two different mechanisms of immunity with this assay. The overall average of $C$.albicans and E.coli killing were both significantly higher in 2013 than in 2012, which may 
be related to the heavier cone crop in 2013 (Figure 6). 3) Results from white blood cell differentials: From the blood smears, we were able to detect distinct annual variation of average white blood cell levels in red crossbills (Figure 7).

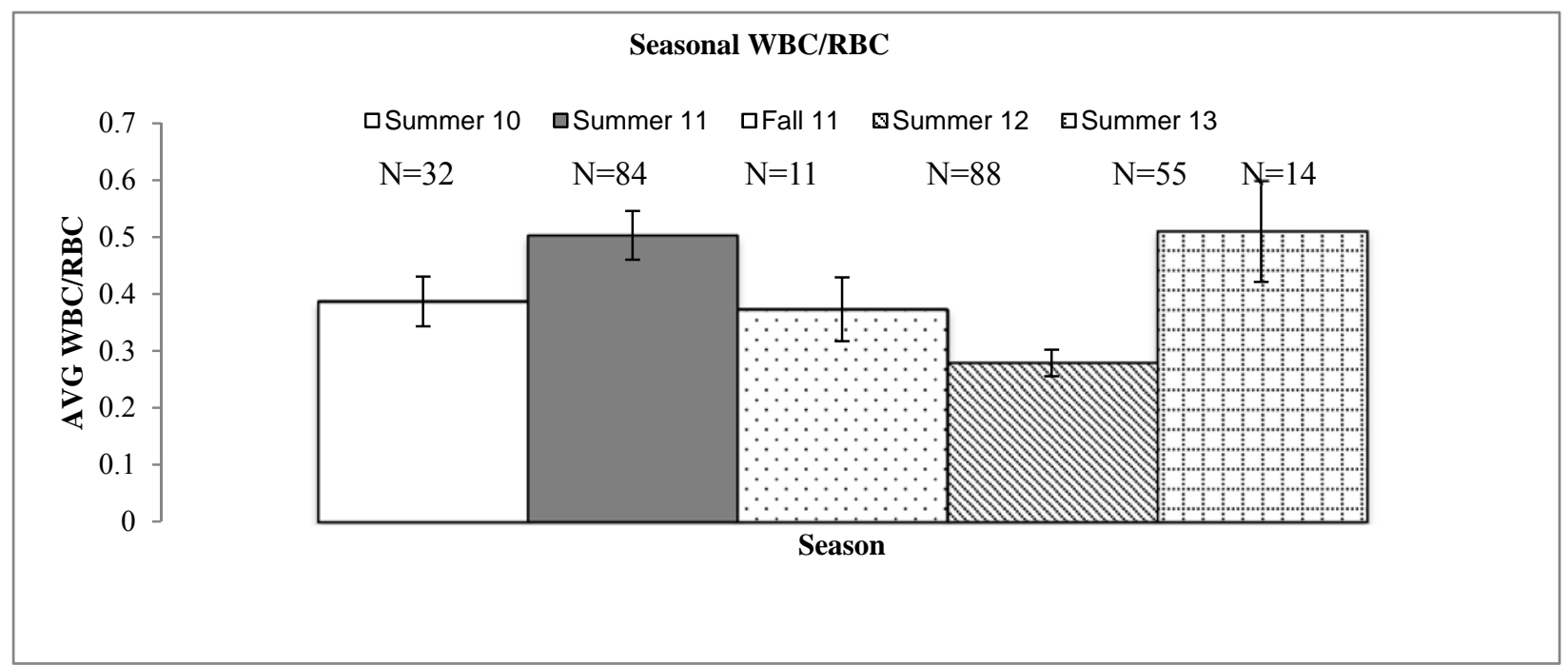

Figure 7. Seasonal pattern of white blood cell/ red blood cell ratios. Highest WBC/RBC ratios are seen in the summer, with declining scores occurring in fall, winter, and spring. WBC/RBC ratios are also higher in years with heavy cone crops (2011, 2013). Bars represent S.E.M.

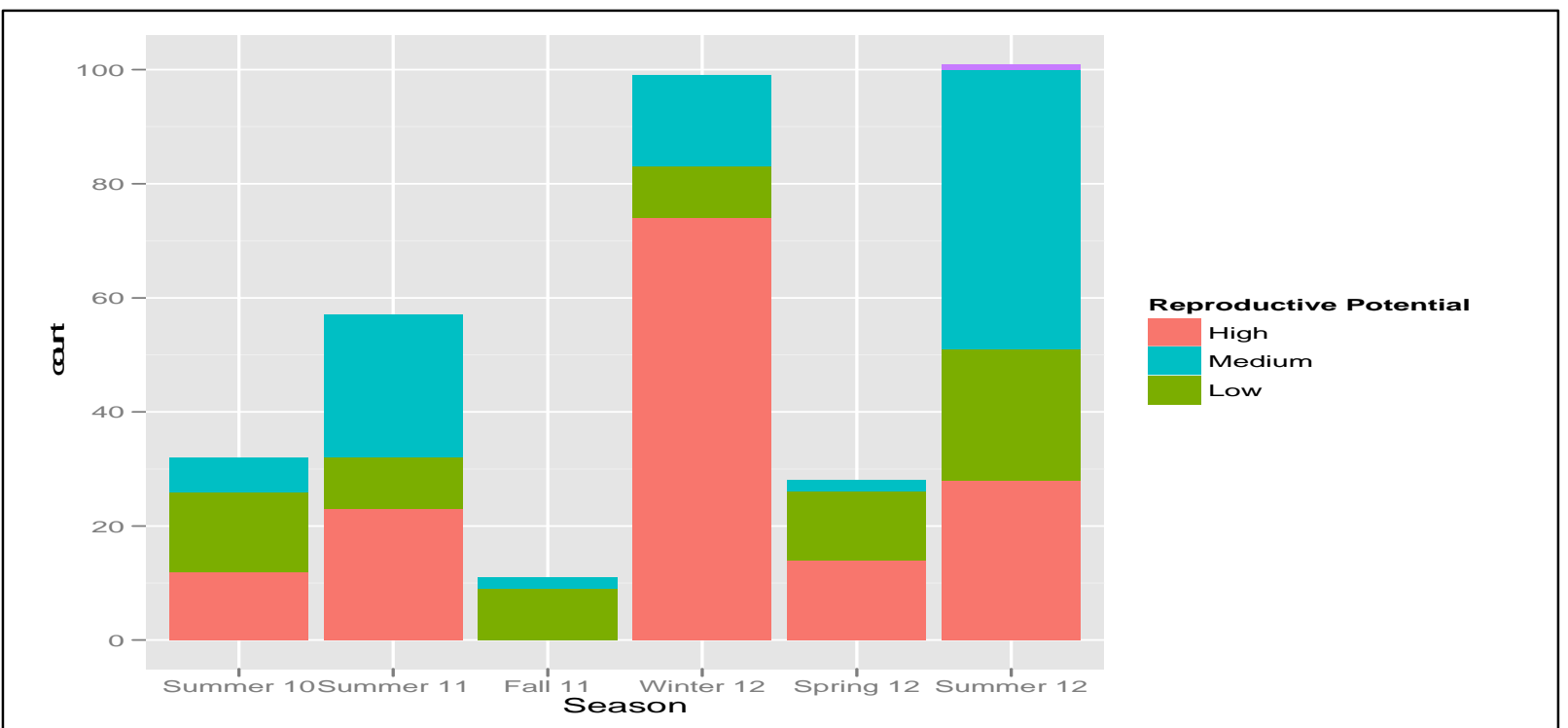

Figure 8. Crossbill reproductive potential (both males and females) across seasons. The largest proportion of crossbills categorized as having high reproductive potential was seen in the winter of 2012 (heavy cone year), and lowest generally seen in the fall and in summers of low cone years $(2010,2012)$. Data from 2013 not shown.

\section{How size of cone crops affects crossbill investment in reproduction}

Overall, crossbills invest more in reproduction (higher reproductive potential as measured by larger cloacal protuberances and presence of spermatozoa in males, and brood patch appearance in females), when cone crop levels are high, regardless of the other environmental conditions (temperature, precipitation levels) (Figure 8). As demonstrated above, in heavy cone years, crossbills are able to maintain high levels of immunity as well as investing significantly in reproduction, suggesting that with adequate resources, crossbills are able to maintain both physiological processes without exhibiting any tradeoffs. 


\section{Overall conclusions}

Based on our data collected in 2010-2013 we have augmented our 20 year field data set on red crossbills, further confirming that fluctuations in conifer cone crop size and the overall conifer species diversity affect multiple aspects of red crossbill physiology. Heavy cone years like 2011 that saw large cone crops specifically on Douglas-firs, Engelmann and blue spruces (lodgepole pine saw relatively static cone crops from year-to-year), positively affected two aspects of immunity (lysis scores and white blood cell counts), as well as increasing reproductive potential in both males and females. Additionally, red crossbills had overall higher immunity and higher reproductive potential during heavy cone years, suggesting that when food resources are plentiful, crossbills are able to sustain both costly physiological processes without tradeoffs. According to our model-selection approach, the highest-ranking model predicting seasonal variation in lysis score and white blood cell counts included positive effects of cone crop scores (heavier cone crops increased scores) and temperature.

\section{BROADER IMPACTS}

Because crossbills are not entirely dependent on conifer seed abundance to maintain survival and even reproduction, food scarcity may not be the only driving factor influencing selection on their adaptive radiation. Thus, it is important to investigate how the diversity and abundance of conifer species may influence resource allocation to reproduction and selfmaintenance in different vocal types of red crossbills. Additionally, how dependent red crossbills are on conifer species in Grand Teton National Park will have conservation implications as conifer species composition changes within the park. Landscape scale changes in age structure and composition of the forests could have major influences on crossbill populations, both in overall numbers and diversity of vocal types in the park (Kelsey et al. 2008).

In addition, the timing and investment in reproduction and survival have been more extensively investigated in seasonally breeding organisms, with most of these studies focusing on captive animals. Thus, we are limited in our ability to answer questions that involve how demanding environmental conditions such as low food availability may affect investment decisions, specifically in regards to reproduction, because seasonally breeding animals typically breed only when environmental conditions are benign. By studying organisms such as crossbills that are able to reproduce in harsh environmental conditions, we will gain more insight into potentially alternative physiological mechanisms that regulate the timing and investment in survival and reproduction. This information can be applied to understanding how organisms effectively allocate resources to competing physiological processes, which is becoming increasingly important in light of recent anthropogenic changes (Wuethrich 2000, Hughes 2000).

\section{$\downarrow$ ACKNOWLEDGEMENTS}

In addition to generous funding and support from the University of Wyoming and National Park Service in 2012, this project has received funding from NSF grant 0744745 to TPH, and grants from Sigma $\mathrm{Xi}$, Society of Integrative and Comparative Biology, and the American Ornithologists' Union to EMS. This study would not have been possible without the help of SE Knox, DZ Jaul, RE Koch, C Lopez, DG Reichard, JM Cornelius, and KC Klasing. We would also like to thank the UW-NPS Research Station for providing EM Schultz and DG Reichard housing during the summer of 2013, as well as to DZ Jaul, RE Koch, and SE Knox in 2011 and 2012.

\section{LITERATURE CITED}

Adkisson, C. S. 1996. Red Crossbill: Loxia curvirostra. In: A. Poole and F. Gill (eds.), The Birds of North America. The Academy of Natural Sciences, American Ornithologists' Union, Philadelphia, PA.

Andersson, M. 1980. Nomadism and site tenacity as alternative reproductive tactics in birds. Journal of Animal Ecology 49:175184.

Anderson, D. R. 2008. Model-based Inference in the Life Sciences: A Primer on Evidence. $2^{\text {nd }}$ edition. Springer, New York.

Brown, J. H., and C. R. Feldmeth. 1971. Evolution in constant and fluctuating environments: Thermal tolerances of desert pupfish (Cyprinodon). Evolution 25(2): 390-398.

Brown, J. H., D. W. Mehlman, and G. C. Stevens. 1995. Spatial variation in abundance. Ecology 76(7): 2028-2043.

Buehler, D. M., T. Piersma, K. Matson, and B. I. Tieleman. 2008. Seasonal redistribution of immune function in a migrant shorebird: Annual-cycle effects override adjustments to thermal regime. The American Naturalist 172(6): 783-796.

Burns, R. M., and B. H. Honkala. 1990. Silvics of North America, Agricultural Handbook 654. U.S. Forest Service, Department of Agriculture, Washington, DC. 
Campbell, T. W. 2007. Avian Hematology and Cytology. Iowa State University Press, Ames, IA.

Connell, J. H. 1983. On the prevalence and relative importance of interspecific competition: Evidence from field experiments. American Naturalist 122(5): 661-696.

Cornelius, J. M. 2009. Annual schedules, environmental cues and stress physiology in an irruptive, nomadic songbird, the red crossbill (Loxia curvirostra). University of California, Davis.

Dhondt, A. A. 2001. Trade-offs between reproduction and survival in tits. Ardea 89(1): 155-166.

Groth, J. G. 1993. Evolutionary Differentiation in Morphology, Vocalizations, and Allozymes among Nomadic Sibling Species in the North American Red Crossbill (Loxia curvirostra) Complex. University of California Press, Berkeley, CA.

Gwinner, E. 1986. Circannual Rhythms. SpringerVerlag, Berlin.

Hahn, T. P. 1998. Reproductive seasonality in an opportunistic breeder, the red crossbill, Loxia curvirostra. Ecology 79(7): 2365-2375.

Hahn, T., and M. Denny. 1989. Tenacity-mediated selective predation by oystercatchers on intertidal limpets and its role in maintaining habitat partitioning by Collisella-Scabra and Lottia-Digitalis. Marine Ecology Progress Series. 53(1): 1-10.

Hochachka, W. M., and A. A. Dhondt. 2000. Densitydependent decline of host abundance resulting from a new infectious disease. Proceedings of the National Academy of Sciences 97(10): 5303-5306.

Hughes, L. Biological consequences of global warming: Is the signal already apparent? Trends in Ecology and Evolution 15(2): 56-61.

Kelsey, T. R. 2008. Foraging Ecology, Biogeography, and Population Dynamics of Red Crossbills in North America. Doctoral Dissertation, University of California, Davis, Davis, CA.

Koenig, W. D., and J. M. H. Knops. 2000. Patterns of annual seed production by northern hemisphere trees: A global perspective. American Naturalist 155(1): 59-69.

Lee, K. A. 2006. Linking immune defenses and life history at the levels of the individual and the species. Integrative and Comparative Biology 46(6): 1000-1015.

Lochmiller, R. L., and C. Deerenberg. 2000. Tradeoffs in evolutionary immunology: Just what is the cost of immunity? Oikos 88(1): 87-98.
Martin, L. B., Z. M. Weil, and R. J. Nelson. 2008. Seasonal changes in vertebrate immune activity: Mediation by physiological tradeoffs. Philosophical Transactions of the Royal Society of London B: Biological Sciences 363(1490): 321-339.

Matson, K. D., R. E. Ricklefs, and K. C. Klasing. 2005. A hemolysis-hemagglutination assay for characterizing constitutive innate humoral immunity in wild and domestic birds. Developmental and Comparative Immunology 29(3): 275-286.

Menaker, M. 1971. Rhythms, reproduction, and photoreception. Biology of Reproduction 4(3): 295-308.

Millet, S., J. Bennett, K. Lee, M. Hau, and K. C. Klasing. 2007. Quantifying and comparing constitutive immunity across avian species. Developmental and Comparative Immunology 31(2): 188-201.

Monaghan, P., and R. G. Nager. 1997. Why don't birds lay more eggs? Trends in Ecology and Evolution 12(7): 270-274.

Nelson, R. J., and G. E. Demas. 1996. Seasonal changes in immune function. Quarterly Review of Biology 71(4): 511-548.

Nolan Jr, V., and E. D. Ketterson. 1983. An analysis of body mass, wing length, and visible fat deposits of Dark-eyed Juncos wintering at different latitudes. The Wilson Bulletin 95(4): 603-620.

Owen-Ashley, N. T., and J. C. Wingfield. 2006. Seasonal modulation of sickness behavior in free-living northwestern song sparrows (Melospiza melodia morphna). The Journal of Experimental Biology 209: 3062-3070.

Ralph, C. J., S. Droege, and J. R. Sauer. 1995. Managing and monitoring birds using point counts: Standards and applications. In: Monitoring Landbirds with Point Counts. C. J. Ralph, S. Droege, and J. R. Sauer (eds.). U.S. Forest Service, U. S. Department of Agriculture, Albany, CA.

Schmid-Hempel, P., and D. Ebert. 2003. On the evolutionary ecology of specific immune defense. Trends in Ecology and Evolution 18(1): 27-32.

Wingfield, J. C., and D. S. Farner. 1976. Avian endocrinology: Field investigations and methods. Condor 78: 570-573.

Wuethrich, B. 2000. How climate change alters rhythms of the wild. Science 287: 793-795.

Zera, A. J., and L. G. Harshman. 2001. The physiology of life history trade-offs in animals. Annual Review of Ecology and Systematics 32: 95126. 